\title{
Development of Automatic Mixing Process for Fertigation System in Rock Melon Cultivation
}

\author{
Muhammad Khairie Idham Abd Rahman, Salinda Buyamin, M. S. Zainal Abidin, Musa Mohd Mokji
}

Control and Mechatronics Department, Faculty of Electrical Engineering, Universiti Teknologi Malaysia, Malaysia

\begin{tabular}{l}
\hline \hline Article Info \\
\hline Article history: \\
Received Feb 11, 2018 \\
Revised May 2, 2018 \\
Accepted May 11, 2018 \\
\hline
\end{tabular}

Keyword:

Automatics system

Fertigation

Greenhouse

Mixture process

Rock melon fertigation

\begin{abstract}
This work proposed an automatic mixing system of nutrient solution for rock melon fertigation according to the required electrical conductivity (EC) level. Compared to the manual practice, this automatic system will ensure continuous supply of mixed nutrient solution without the need to daily check and mix new nutrient. Thus, this easy to use and low cost automatic system will reduce the burden of the farmers. This system uses an EC sensor to automatically check the concentration level of the mixed nutrient solution. Other than that, the system only consists of electronic pumps for mixing process and an Arduino board as the controller. The controller will monitor the EC level and run the mixing process when the EC level is below the required level. By calibrating the EC sensors, the test shows that the automatic mixing system is able to accurately keep the mixed nutrient solution concentration in a $400 \mathrm{~L}$ mixing reservoir at several required levels.
\end{abstract}

Copyright $(2018$ Institute of Advanced Engineering and Science. All rights reserved.

\section{Corresponding Author:}

Salinda Buyamin,

Control and Mechatronics Department, Faculty of Electrical Engineering,

Universiti Teknologi Malaysia,

UTM Johor Bharu, 81310 UTM Skudai, Johor , Malaysia.

Email: salinda@fke.utm.my

\section{INTRODUCTION}

In agriculture, water and nutrients are two critical inputs for higher crop productivity to produce high income to the farmer [1]-[3]. To effectively feed the water and nutrients, soluble nutrient solution are mixed with the water and feed to the crops via automatic irrigation system [4]-[6]. This method is called fertigation. There are many fertigation system that have been developed commercially, which normally used $\mathrm{pH}$ and electrical conductivity(EC) sensors to determine the correction ratio of water and the nutrient solution [4]. Flow sensor combines with solenoid valves will give signal for volume of water for controlling the ON/OFF period for the fertigation pump. However, these commercial fertigation systems are high maintenance and high cost due to the installation of sophisticated device such as dosing pump and high spec controller [7].

In manual conventional method, mechanical float and portable EC meter are used to fill water into the mixing reservoir at required amount and manually check the nutrient solution concentration respectively. However, this will need the farmer to do the nutrient solution concentration check and mixing every time the solution is to be pumped to the crops. With low maintenance and affordable controller such as Arduino board, automatic mixing system can overcome the problem especially for the small-scale crop size. Another advantage of the automatic mixing system is its ability to maintain the required concentration of the nutrient solution according to the plant growth stages [7]-[11]. With an automated system, the farm operation will be more flexible and the fertigation system will be more efficient to deliver the nutrient solution to the crops [4], [11]-[13]. 
In this work, an automatic mixing process of two stock solutions (A and B) and water as dilution agent was developed using Arduino board as the controller and EC sensor to read the nutrient solution concentration. Other than that, two pumps are used to dose the two stock solutions into the mixing reservoir and one pump is placed inside the mixing reservoir as the mixer. For water, its level is simply controlled with a mechanical float.

\section{RESEARCH METHOD}

\subsection{Portable electrical conductivity sensor}

As the basis of the mixing system, Analog EC Meter SKU: DFR0300 EC sensor module from DFRobot shown in Figure 1 is used for this work. The EC measures the potential for an electrical current to be transported through water known as molar conductivity (electrolytic conductivity). It can be reflected to the level of the electrolytes present in the water. The module includes the Arduino IO expansion shield to ease the difficulty of using the sensor. Other than that, also included is the waterproof DS18B20 temperature sensor, which is used to calibrate the EC reading according to temperature. The code for the temperature based calibration method is supplied by the manufacturer through online materials. However, since the method of reading the EC value supplied by the manufacturer is not suitable for the application of this work, a modification was made and another calibration process was added. This will be explained in later discussion.

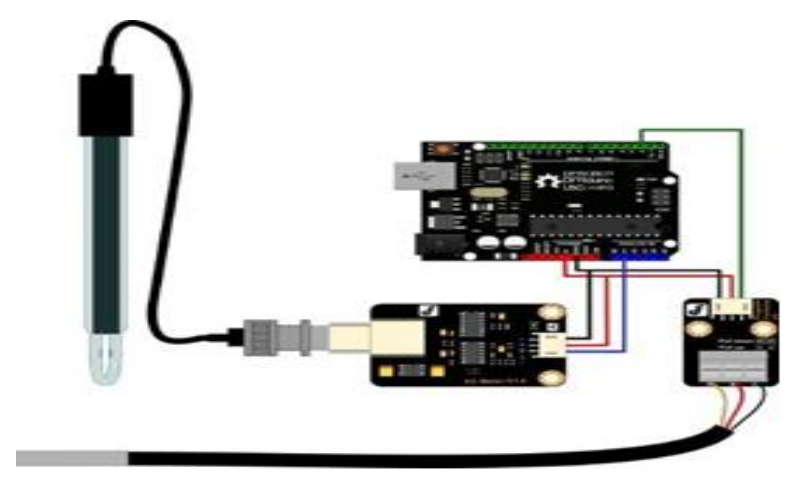

Figure 1. EC sensor

\subsection{Operation of the system}

The system was developed on mixing reservoir with capacity of $400 \mathrm{~L}$. However, the proposed system is not limited to other capacities of mixing reservoir. Also, two $100 \mathrm{~L}$ reservoir were used to store the stocks nutrients $\mathrm{A}$ and $\mathrm{B}$. Water for the stock nutrients dilution is filled into the mixing reservoir from the main water pipe. Figure 2 shows the layout of the system. Pump A and B, which are used to flow the stock nutrients into the mixing reservoir are $4.2 \mathrm{~W}$ water pumps with a flow rate of 240 liter/hour rated at $12 \mathrm{~V}$.

The controller used for the system is Arduino Uno board. This controller is chosen for its low cost and easy for coding. Besides, the board is also easy to configure with many sensors and actuators including the EC sensor meter and pumps used in this work.

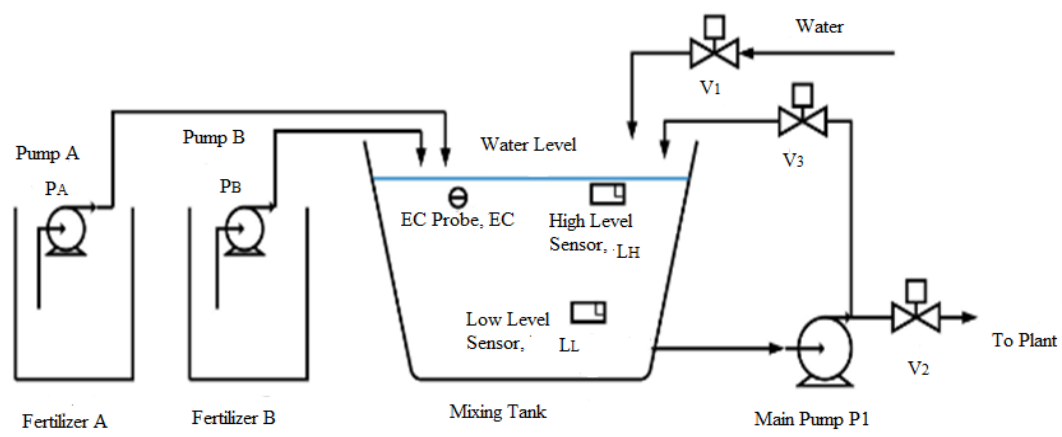

Figure 2. The layout of the nutrient mixing system 
The nutrient solution mixing process is described by the pseudo-code shown in Figure 3 where user can set the required EC level (SetEC). Other than that, the effectiveness of the mixing process can be configured by setting the EC reading difference value (ECDiffThreshold) and mixing time interval (MixTime). The ECDiffThreshold is a parameter set to indicate when will the mixing process settled. Basically, the mixing process will start when the EC reading on the nutrient solution fall below the SetEC value. First, the required amount of time to pump the stock nutrients A and B will be computed. Then after the stock nutrients pumped into the mixing reservoir according to the computed time, the mixing pump will be on and turned off when the mixing settled (EC value difference goes below the ECDiffThreshold). Based on several tests, the best ECDiffThreshold and MixTime values are 100 and 10000 respectively. However, to have the best result, these values could be different for different mixing reservoir capacity. Figure 4 shows the flow process of the automatic mixing process.

To have an accurate EC value reading, the 'read current EC value' step is consisting of two stages, averaging and calibration. Averaging is the process of reducing fluctuation from the EC sensor by taking several readings and average them out. Then, calibration is the process of converting the average value into a more reasonable value based on the predetermined calibration parameters. The calibration was made on the actual size system where the linear regression between the readings from the sensor and a meter was plotted. Parameters obtained from the linear regression is used to convert the actual sensor reading into a more accurate value according to the EC meter.

Referring to line 10 of the pseudo-code, the equation to estimate the time taken to pump the stock nutrient to the mixing reservoir will be discussed further in Section 3.1.

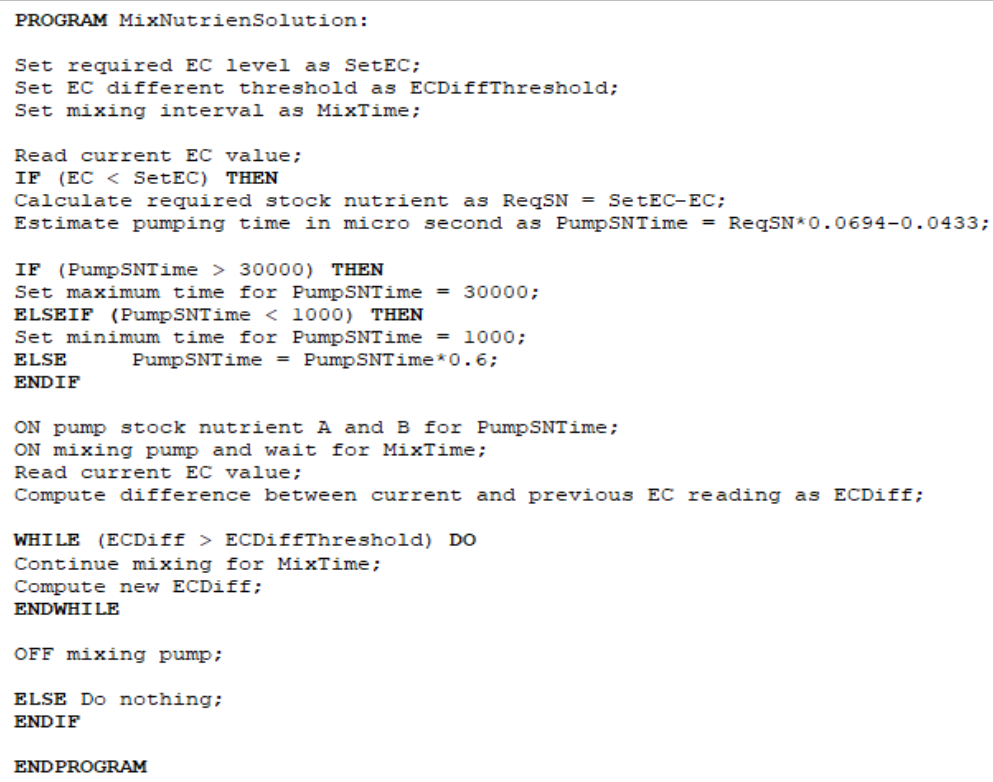

Figure 3. Mixing process

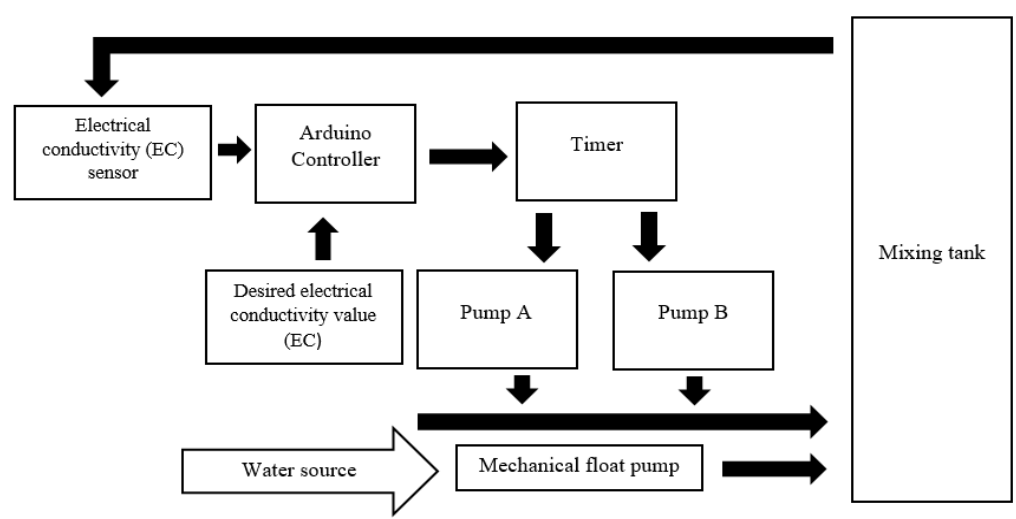

Figure 4. Schematic diagram for nutrient mixing for fertigation system 


\subsection{Fertilizer and irrigation scheduling}

Different crop need different nutrient solution concentration. The nutrient solution concentration that is too low or too high will affect the plant growth if not monitored. Table 1 shows the list of the concentration level proposed for the rock melon for one season. It can be seen that there are several EC level throughout the cultivation process. Thus, the proposed mixing system should be able to prepare different EC levels of the nutrient solution.

Table 1. EC Level for Rock Melon Cultivation

\begin{tabular}{cc}
\hline Weeks & EC(dS/m) \\
\hline 1 & 1.6 \\
2 & 1.9 \\
3 & 2.1 \\
4 & 2.4 \\
5 & 2.7 \\
6 & 3.0 \\
7 & 3.3 \\
8 & 3.5 \\
9 & 3.8 \\
10 & 3.8 \\
\hline
\end{tabular}

\section{RESULTS AND ANALYSIS}

In this work, the performance of the system is measured at two stages. First is to measure the reading precision of the EC sensor alone based on the proposed sensor reading method described in Figure 3. Second, the performance of the system is measured on the whole system where the EC sensor act as the input to the system to start and stop the mixing process.

\subsection{EC sensor precision}

Precision of the Analog EC Meter SKU: DFR0300 is measured by calculating the relationship of the EC value on several volumes of water. The measurement result (Figure 5) shows the linearity of EC and nutrient volume even at the different volume of water. This test was purposely done to determine the regression between the volume of water and nutrient to the desired EC at different volume of water.

The original code supplied with the EC meter is reading the EC value by averaging the current value with all previous recorded values. The method works when there is no rapid change on the volume of the nutrient solution, which is mixed with the water. However, with rapid flow of the nutrient solution into the water to be mixed, the actual EC value will rapidly change. This is where the original reading method of the EC sensor will have a critical delay to achieve actual EC value. To achieve a more accurate reading, this work takes an average of the last three reading and ignore a reading when it is identified as an outlier. Besides the regression values as previously discussed, Figure 5 shows that the proposed averaging method gives a smooth reading, similar to the original method. The smoothness of the reading is getting better when the volume of water increased.

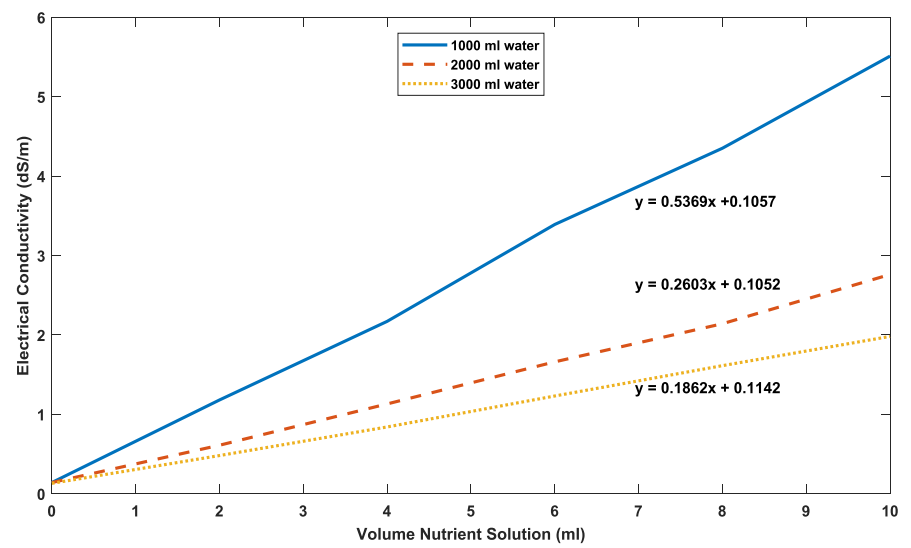

Figure 5. Relationship between EC and fertilizer volume 
To further test the precision of the sensor reading method, time needed to pump the stock nutrient A and $\mathrm{B}$ to the mixing reservoir was performed. This test used 100L reservoir for each of the stock nutrients and $4.2 \mathrm{~W}$ water pumps with a flow rate of 240 liter/hour rated at $12 \mathrm{~V}$ in each of the reservoirs. From Figure 6, it shows that the amount of time it takes to mix nutrient was less than one minute to achieved EC value equals to $3.5 \mathrm{dS} / \mathrm{m}$, which is the maximum EC value commonly used by farmers. This shows that the EC values read by the sensor is now fast enough for the normal speed of the mixing process. From Figure 6, the linear regression parameter is used to formulate the time estimation formula written in the pseudo-code shown in Figure 3.

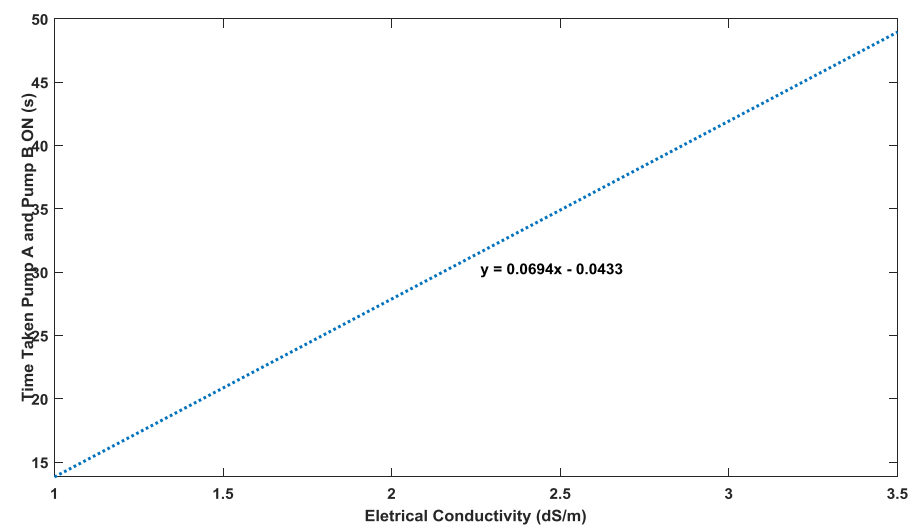

Figure 6. Relationship between EC and time taken to pump the nutrient solution

\subsection{Overall system test}

In this test, the system is run on full operation where fresh water is automatically flowing in when needed and the mixing process by flowing the water using submersible pump is running. Figure 7 shows the EC reading of the reaction of the automated mixture nutrient with desired EC $1 \mathrm{dS} / \mathrm{m}$ and $2.7 \mathrm{dS} / \mathrm{m}$. The system can mix the nutrient but there is a slight different reading with the desired input system and the controller needed to take time to achieve the desired EC. This is representing consistent average steady sate error close to $10 \%$ of the actual desired EC value. Since the error is consistent, thus the system can be said to be working as expected where the error is easily handle by linearly mapping it to the actual value.

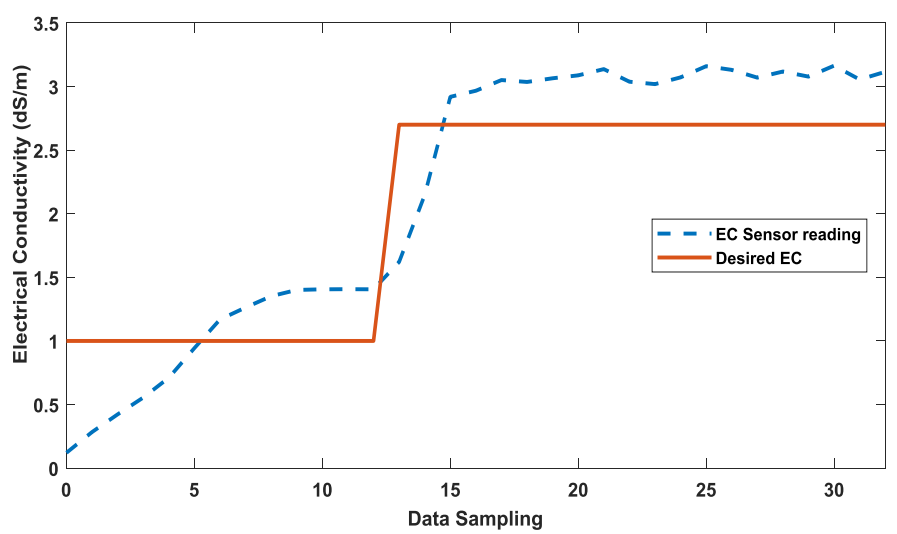

Figure 7. Result for controller test on real system

\section{CONCLUSION}

A fertigation controller with automatics mixing process have been developed where the system is able to provide continuous supply of nutrient solution at desired EC level. The low-cost devices and components use to develop the system allows more farmers including the small-scale producers to control 
and monitor the nutrient solution level based on the plant growth stage. The test on $100 \mathrm{~L}$ reservoir for each of the stock nutrients and $4.2 \mathrm{~W}$ water pumps with a flow rate of 240 liter/hour rated at $12 \mathrm{~V}$ in each of the reservoirs shows that the amount of time it takes to mix nutrient was less than one minute to achieved EC value equals to $3.5 \mathrm{dS} / \mathrm{m}$, which is the maximum EC value commonly used by farmers. Although the system shows $10 \%$ average for the steady state error of the desired EC value, it can be said that the system is working well. In addition to this, this controller is low at maintenance and can be improved with the integration of internet of thing (IoT) devices to have a cognitive processing to the system.

\section{ACKNOWLEDGEMENTS}

The authors gratefully acknowledged the Ministry of Higher Education (Vote No. Q. J130000.2523.17H45) and Universiti Teknologi Malaysia for the financial supports through University Research Grant Scheme.

\section{REFERENCES}

[1] S. A. H. Z. Abidin and S. Noorjannah Ibrahim, "Web-based monitoring of an automated fertigation system: An IoT application," 2015 IEEE 12th Malaysia Int. Conf. Commun. MICC 2015, no. Micc, pp. 1-5, 2016.

[2] S. Navulur, S. Navulur, C. S. S. AS, and G. P. MN, "Agricultural Management through Wireless Sensors and Internet of Things,” Int. J. Electr. Comput. Eng., vol. 7, no. 6, p. 3492, 2017.

[3] T. H. Zhao, P. F. Zhang, and H. M. Hou, "The Agricultural Irrigation District Information System based on MultiAgent and GSM," Adv. Mechatronics Control Eng. Ii, Pts 1-3, vol. 433-435, no. 5, pp. 1853-1856, 2013.

[4] R. B. Singandhupe, G. G. S. N. Rao, N. G. Patil, and P. S. Brahmanand, "Fertigation studies and irrigation scheduling in drip irrigation system in tomato crop (Lycopersicon esculentum L.)," Eur. J. Agron., vol. 19, no. 2, pp. 327-340, 2003.

[5] G. Sun et al., "Design and testing of a nutrient mixing machine for greenhouse fertigation," Eng. Agric. Environ. Food, vol. 8, no. 2, pp. 114-121, 2015.

[6] D. Hanitha, B. Anusha, and M. D. Prakash, "FPGA Implementation of Automatic Irrigation and Pesticide Control System," vol. 5, no. 3, pp. 136-140, 2016.

[7] A. J. Steidle Neto, S. Zolnier, and D. de Carvalho Lopes, "Development and evaluation of an automated system for fertigation control in soilless tomato production," Comput. Electron. Agric., vol. 103, pp. 17-25, 2014.

[8] J. Ruan, P. Liao, and C. Dong, "The Design and Research on Intelligent Fertigation System," 2015 7th Int. Conf. Intell. Human-Machine Syst. Cybern., pp. 456-459, 2015.

[9] S. F. M. Samsuri, R. Ahmad, and M. Hussein, "Development of nutrient solution mixing process on time-based drip fertigation system," AMS2010 Asia Model. Symp. 2010 - 4th Int. Conf. Math. Model. Comput. Simul., pp. 615-619, 2010.

[10] G. Bankar, “Automated Irrigation and Fertigation System," Int. J. Electr. Electron. Res., vol. 4, no. 2, pp. 193-197, 2016.

[11] B. Kaur and D. Kumar, "Development of Automated Nutrients Composition Control," Int. J. Comput. Sci. Eng. Appl., vol. 3, no. 3, pp. 67-78, 2013.

[12] A. Perez-Castro, J. A. Sanchez-Molina, M. Castilla, J. Sanchez-Moreno, J. C. Moreno-Ubeda, and J. J. Magan, "cFertigUAL: A fertigation management app for greenhouse vegetable crops," Agric. Water Manag., vol. 183, pp. 186-193, 2017.

[13] J. E. M. Salih, A. H. Adom, and A. Y. M. Shaakaf, "Solar Powered Automated Fertigation Control System for Cucumis Melo L. Cultivation in Green House,” APCBEE Procedia, vol. 4, pp. 79-87, 2012.

\section{BIOGRAPHIES OF AUTHORS}

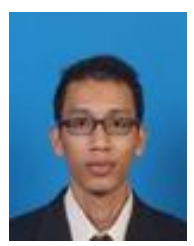

Muhammad Khairie Idham Abd Rahman recived his B. Eng in Electrical Engineering majored in Control and Mechatronics from Universiti Teknologi Malaysia (UTM) in 2016. Currently, he is pursuing his studies in Master of Philosophy of Electrical Engineering and his interest is in adaptive control for precision agricultural system for water saving.

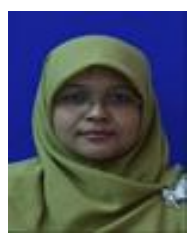

Salinda Buyamin received her B. Eng in Electrical Engineering from University of Toledo, USA in 1998, Msc in Automation and Control (Distinctio) from University of Newcastle, United Kingdom in 2003 and $\mathrm{PhD}$ in Control of Electrical Drives from University of Newcastle, United Kingdom in 2007. Currently, she is an Associate Professor at Universiti Teknologi Malaysia (UTM) in Control and Mechatronics Department, Faculty of Electrical Engineering and her current research interest involve the Modelling and Simulation of Dynamic Systems, Control and Development of Electric Drives System, System Identification and Estimation, Optimisation, Intelligent Control, Sensorless 
Control and Smart Agriculture System.
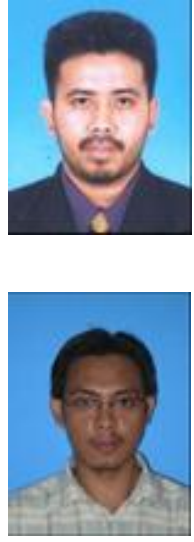

Mohamad Shukri Zainal Abidin received his B. Eng in Electrical Engineering from Universiti Teknologi Malaysia (UTM) in 1998, Msc in Electrical Engineering from Universiti Teknologi Malaysia (UTM) in 2001 and $\mathrm{PhD}$ in Agriculture Engineering from Tokyo University of Technology, Japan in 2014. Currently, he is a Senior Lecturer at Universiti Teknologi Malaysia (UTM) in Control and Mechatronics Department, Faculty of Electrical Engineering and his current research interest involve the adaptive control strategies in fibrous capillary irrigation system and agricultural robotics.

Musa Mohd Mokji received his B. Eng in Electrical Engineering in 2000, Msc in Image Processing in 2002 and $\mathrm{PhD}$ in Image Processing in 2008 from Universiti Teknologi Malaysia. Currently, he is a Senior Lecturer at Universiti Teknologi Malaysia (UTM) in Electronics and Computer Engineering Department, Faculty of Electrical Engineering and his current research interest involve the Pattern Recognition, Image Processing, Cognitive Processing, IoT Sensor and Smart Agriculture System. 